\title{
Intra-Articular Hyaluronic Acid as Treatment in Elderly and Middle- Aged Patients with Knee Osteoarthritis
}

\author{
Demet Uçar ${ }^{*}, 1$, Demirhan Diraçoğlu ${ }^{2}$, Türker Süleyman ${ }^{2}$ and Nalan Çapan ${ }^{2}$ \\ ${ }^{I}$ Department of Physical Medicine and Rehabilitation, Dicle University Medical Faculty, Diyarbakir, Turkey \\ ${ }^{2}$ Department of Physical Medicine and Rehabilitation, Istanbul University Medical Faculty, İstanbul, Turkey
}

\begin{abstract}
Introduction: Osteoarthritis is the most common age-related degenerative joint disease. It affects all the joints containing hyaline cartilage. Knee osteoarthritis is the most cumbersome in terms of prevalence and disability. The aim of this study to evaluate the efficacy of intra-articular hyaluronic acid in patients with knee osteoarthritis with regard to joint pain and function, as well as patient satisfaction, assessed at one month and at one year, and by age group.

Methods: In this prospective randomised study, 172 patients who were diagnosed knee OA and who received three consecutive intra-articular injections of HA weekly were included. Patients 65 years of age or older were accepted as the "elderly group", and those under 65 were accepted as the "middle-aged group". Clinical evaluations of efficacy and safety were conducted at the beginning of the study, one month after the third injection, and one year after the third injection.

Results: In the two groups, the intragroup analysis revealed significant improvements following injection when compared with preinjection values. According to the last followup controls (after 12 months) in the middle-aged group, VAS activity pain, VAS rest pain, WOMAC physical function, and WOMAC pain values were found to be statistically lower when compared with pre-injection values. In the elderly group, no statistically significant differences were found between preinjection and after 12 months.

Conclusion: We can conclude that intra-articular joint HA injections are effective in both young and old patients with OA with regard to pain and functional status over a short-term period. Further, HA injections in patients younger than 65 years can be planned for a one-year period.
\end{abstract}

Keywords: Knee osteoarthritis, hyaluronic acid, knee pain.

\section{INTRODUCTION}

Osteoarthritis (OA) is the most common age-related degenerative joint disease and one of the most important health problems in the world. It affects all the joints containing hyaline cartilage. Although OA can affect any synovial joint, $\mathrm{OA}$ of the knee joints is the most cumbersome in terms of prevalence and disability [1]. Primary symptoms of the disease are pain and tenderness in the joint [2]. Hyaluronic acid (HA), a mucopolysaccharide comprised of tandem repeats of D-glucuronic acid and $\mathrm{N}$-acetyl glucosamine, is abundantly present in synovial fluid [3]. Intra-articular administration of $\mathrm{HA}$ is the treatment of choice for patients with symptomatic knee OA [4]. The effects of HA have been reported up to one year in most studies; however, age-related outcomes in knee OA have not been emphasized as much as they should [4-7]. Because the effect of age on treatment effectiveness has not been assessed much in previous studies, it might be interesting to gather data on this particular issue. Thus, we aimed to evaluate the efficacy of intra-articular HA in patients with knee OA with regard to joint pain and function, as well as

*Address correspondence to this author at the Dicle University Medical Faculty, Diyarbakır, Turkey; Tel: 00904122488001 ;

Fax: 0090 4122488111; E-mail: drdemetucar@yahoo.com patient satisfaction, assessed at one month and at one year, and by age group ( 65 and over and under 65 ).

\section{PATIENTS AND METHODS}

In this prospective randomised study, 172 patients who were diagnosed knee OA according to the American College of Rheumatology (ACR) criteria [8] and were classified with radiological stage II or III according to the Kellgren and Lawrence classification [9] were recruited from the medical files in our outpatient injection clinic.

Patients who received three consecutive intra-articular injections of $\mathrm{HA}(30 \mathrm{mg} / 2 \mathrm{ml})$ weekly were included in the study. The knee joint injections were performed under sterile conditions by inserting a 21-gauge needle into the patellofemoral joint space by superolateral approach while the patients were in a supine position. Patients 65 years of age or older were accepted as the "elderly group" $(\mathrm{n}=71)$, and those under 65 were accepted as the "middle-aged group" ( $\mathrm{n}=101)$. In both groups, pain level during activity and at rest was measured using a visual analog scale (VAS). Western Ontario and McMaster University Osteoarthritis Index (WOMAC 5-point Likert 3.0) [10] and VAS were used to analyze pain, stiffness, disability, and functional status. Clinical evaluations of efficacy and safety were conducted at the beginning of the study, one month after the third injection, and one year after the third injection. At 
month 12, a followup telephone interview was conducted by the evaluator to assess long-term efficacy and safety. The patients were questioned during the followup telephone interview regarding adverse signs and symptoms that had emerged during the study period. Exclusion criteria were previous intra-articular injections, history of knee trauma or knee surgery, inflammatory knee disorders, metabolic bone disease, serious systemic disease, depression, neoplasm, and effusion in the knee.

Outcome measures were analyzed using the SPSS package; data was shown as mean plus/minus standard deviation. We used a chi-square test to compare the radiological grades of the cases of the two groups. An independent samples t-test was used to compare the WOMAC and VAS scores of the two groups. Intra-group comparisons before and after the injections were measured by using a paired sample $t$ test. A p-value less than 0.05 was accepted as statistically significant.

\section{RESULTS}

The mean age was 71.3 years (65-84) in the elderly group and 54.5 years (34-64) in the middle-aged group. According to the Kellgren and Lawrence classification, the cases of the two groups and gender of the patients were found correlated (Table 1). Pre-injection values of the patients are summarized in Table $\mathbf{2}$. The two groups were statistically similar in this regard.

Table 1. Radiological Grades and Genders of the Patients

\begin{tabular}{|c|c|c|c|c|c|}
\hline & $\begin{array}{c}\text { Grade II } \\
(\mathbf{n})\end{array}$ & $\begin{array}{c}\text { Grade III } \\
(\mathbf{n})\end{array}$ & $\begin{array}{c}\text { Female } \\
(\mathbf{n})\end{array}$ & $\begin{array}{c}\text { Male } \\
(\mathbf{n})\end{array}$ & $\begin{array}{c}\text { Total } \\
(\mathbf{n})\end{array}$ \\
\hline \hline Middle-age group & 36 & 65 & 74 & 27 & 101 \\
\hline Elderly group & 24 & 47 & 56 & 15 & 71 \\
\hline P value & \multicolumn{2}{|c|}{0.803} & \multicolumn{3}{|c|}{0.399} \\
\hline
\end{tabular}

Table 2. Pre-Injection Values in the Two Groups

\begin{tabular}{|c|c|c|c|}
\hline & $\begin{array}{c}\text { Middle-Age } \\
\text { Group }\end{array}$ & $\begin{array}{c}\text { Elderly } \\
\text { Group }\end{array}$ & $\begin{array}{c}\text { P } \\
\text { Value }\end{array}$ \\
\hline \hline VAS resting pain & $4.4 \pm 2.9$ & $4.4 \pm 2.8$ & 0.963 \\
\hline VAS activity pain & $7.3 \pm 1.8$ & $7.6 \pm 1.8$ & 0.317 \\
\hline WOMAC pain & $4.9 \pm 1.7$ & $5.1 \pm 1.8$ & 0.608 \\
\hline WOMAC stiffness & $4 \pm 2.6$ & $4.4 \pm 2.3$ & 0.309 \\
\hline WOMAC physical function & $4.9 \pm 1.9$ & $5.3 \pm 1.8$ & 0.167 \\
\hline WOMAC total & $13.7 \pm 5.2$ & $14.7 \pm 4.8$ & 0.206 \\
\hline
\end{tabular}

In the two groups, the intragroup analysis revealed significant improvements in VAS activity pain, VAS rest pain, WOMAC pain, WOMAC stiffness, WOMAC physical function, and WOMAC total values following injection when compared with preinjection values (Tables $\mathbf{3}$ and 4). Although not statistically significant $(p>0.05)$, the comparison of the differences (pre-injection/post-injection) between the groups revealed higher values in the middleaged group.
Table 3. Post-Injection Values in the Middle-Age Group

\begin{tabular}{|c|c|c|}
\hline & Postinjection & P Value * \\
\hline \hline VAS resting pain & $2.6 \pm 2.4$ & $<0.001$ \\
\hline VAS activity pain & $5.3 \pm 2.5$ & $<0.001$ \\
\hline WOMAC pain & $3.7 \pm 1.9$ & $<0.001$ \\
\hline WOMAC stiffness & $2.6 \pm 1.7$ & $<0.001$ \\
\hline WOMAC physical function & $3.9 \pm 1.9$ & $<0.001$ \\
\hline WOMAC total & $10.4 \pm 5.3$ & $<0.001$ \\
\hline *: Comparison with the pre-injection
\end{tabular}

*: Comparison with the pre-injection values.

Table 4. Post-Injection Values in the Elderly Group

\begin{tabular}{|c|c|c|}
\hline & Postinjection & P Value * \\
\hline VAS resting pain & $2.4 \pm 2.3$ & $<0.001$ \\
\hline VAS activity pain & $4.6 \pm 2.2$ & $<0.001$ \\
\hline WOMAC pain & $3.5 \pm 1.4$ & $<0.001$ \\
\hline WOMAC stiffness & $3.1 \pm 1.9$ & $<0.001$ \\
\hline WOMAC physical function & $3.6 \pm 1.5$ & $<0.001$ \\
\hline WOMAC total & $10.1 \pm 4$ & $<0.001$ \\
\hline
\end{tabular}

According to the last followup controls (after 12 months) in the middle-aged group, VAS activity pain, VAS rest pain, WOMAC physical function, and WOMAC pain values were found to be statistically lower when compared with preinjection values, while no significant differences were detected in WOMAC stiffness and WOMAC total values (Table 5). In the elderly group, no statistically significant differences were found between pre-injection and after 12 months (Table 6).

Table 5. Values After 12 Months in the Middle-Age Group

\begin{tabular}{|c|c|c|}
\hline & After 12 Months & P Value * \\
\hline VAS resting pain & $3.7 \pm 2.5$ & $<0.001$ \\
\hline VAS activity pain & $7 \pm 1.9$ & 0.001 \\
\hline WOMAC pain & $4.8 \pm 1.8$ & 0.009 \\
\hline WOMAC stiffness & $3.9 \pm 2.1$ & 0.466 \\
\hline WOMAC physical function & $4.8 \pm 1.9$ & 0.004 \\
\hline WOMAC total & $13.5 \pm 4.8$ & 0.11 \\
\hline
\end{tabular}

No adverse events occurred in any of the patients due to the injections.

\section{DISCUSSION}

In 1934, Meyer and Palmer isolated a polysaccharide from bovine vitreous humor and named it hyaluronic acid [3]. The first therapeutic studies of viscosupplementation with HA in knee OA in humans were reported by Rydell and 
Balazs [11]. In recent years, viscosupplementation with HA products has been used frequently in the management strategy of primary knee OA [12-16].

Table 6. Values After 12 Months in the Elderly Group

\begin{tabular}{|c|c|c|}
\hline & After 12 Months & P Value * \\
\hline VAS resting pain & $4.3 \pm 2.7$ & 0.103 \\
\hline VAS activity pain & $7.5 \pm 1.8$ & 0.32 \\
\hline WOMAC pain & $5 \pm 1.7$ & 0.083 \\
\hline WOMAC stiffness & $4.2 \pm 2.1$ & 0.07 \\
\hline WOMAC physical function & $5.2 \pm 1.6$ & 0.321 \\
\hline WOMAC total & $14.4 \pm 5.2$ & 0.161 \\
\hline
\end{tabular}

A meta-analysis by Aggrawal [17] reported that administration of viscosupplementation with HA to the knee joint is a good therapeutic choice in patients who do not respond to conservative treatment or who are not eligible for surgery. In their recent meta-analysis of randomized controlled trials, Wang et al. [13] confirmed that intraarticular injection of HA can decrease symptoms of knee OA. We observed good outcomes in our study as well.

The impact of age and radiological degree of osteoarthritis on clinical efficacy is unclear. To date, the ideal candidate for intra-articular visco supplementation has yet to be clearly defined, with the majority of clinical studies treating patients over 60 years of age with moderate to severe OA. Despite clinical evaluations, age, symptoms, and disease severity have not proven helpful in identifying the patients who might benefit the most. Some studies suggest that patients older than 65 years and with those with advanced radiographic stage arthritis were less likely to benefit from intra-articular injection of HA $[13,18]$. However, other studies have suggested the opposite, in favor of an older population with more severe knee disease, as these patients may be more sensitive in detecting an analgesic effect $[19,20]$. In this study, we are unable to provide any additional information about severe disease (Grade IV), as all the cases were grade II or III. We found a better outcome in the middle-aged group. In particular, the results after 12 months were better in patients younger than 65 years.

In one meta-analysis, it was demonstrated that significant improvements, with limited undesirable effects, were found in terms of activity pain, resting pain, and functional status [13]. However, Arrcih et al. [21] indicated that most of the relevant trials had low methodological quality and that, although HA was superior to placebos with respect to the effects on activity pain, it was not effective on resting pain and did not enhance joint function. Significant improvements in pain, functional status, and duration of pain-free walking have been observed in such studies [21-24]. Our postinjection results demonstrated that intra-articular HA injection in either of these two groups might provide significant improvements in VAS activity, VAS rest, and WOMAC total. Moreover, after 12 months, beneficial effects were seen in the middle-aged group in terms of VAS activity, VAS rest, WOMAC pain, and WOMAC physical function. The most important limitation of our trial was the lack of long-term followup; as such, our results are applicable for patients with grade II or III.

\section{CONCLUSION}

To summarize, in light of our results, we can conclude that intra-articular joint HA injections are effective in both young and old patients with OA with regard to pain and functional status over a short-term period. Further, HA injections in patients younger than 65 years can be planned for a one-year period. Long-term followup results after such injections remain to be investigated in future studies.

\section{CONFLICT OF INTEREST}

The authors confirm that this article content has no conflict of interest.

\section{ACKNOWLEDGEMENTS}

Declared none.

\section{REFERENCES}

[1] Oliveria SA, Felson DT, Reed JI, Cirillo PA, Walker AM Incidence of symptomatic hand, hip, and knee osteoarthritis among patients in a health maintenance organization. Arthritis Rheum 1995; 38: 1134-41.

[2] Uçar D, Bozkurt M. Current treatment methods in osteoarthritis. J Clin Exp Invest 2012; 3(1): 137-40.

[3] Meyer K, Palmar JW. The polysaccharide of the vitreous humour. J Biol Chem 1934; 107: 629-34.

[4] Peyron JG, Balazs EA. Preliminary clinical assessment of Nahyaluronate injection into human arthritic joints. Pathol Biol 1974; 22: 731-6.

[5] Dougados M, Nguyen M, Listrat V, Amor B. High molecular weight sodium hyaluronate (hyalectin) in osteoarthritis of the knee: a 1 year placebo-controlled trial. Osteoarthr Cartil 1993; 1: 97-103.

[6] Raynauld JP, Torrance GW, Band PA, et al. A prospective, randomized, pragmatic, health outcomes trial evaluating the incorporation of hylan G-F 20 into the treatment paradigm for patients with knee osteoarthritis (part 1 of 2): clinical results. Osteoarthr Cartil 2002; 10: 506-17.

[7] Raman R, Dutta A, Day N, Sharma HK, Shaw CJ, Johnson GV. Efficacy of Hylan G.-F 20 and Sodium Hyaluronate in the treatment of osteoarthritis of the knee-a prospective randomized clinical trial. Knee 2008; 15: 318-24.

[8] Altman R, Asch E, Bloch D, Bole G, et al. Development of criteria for the classification and reporting of osteoarthritis. Classification of osteoarthritis of the knee, diagnostic and therapeutic criteria Committee of the American Rheumatism Association. Arthritis Rheum 1986; 29: 1039-49.

[9] Kellgren JH, Lawrence JS. Radiological assessment of osteoarthrosis. Ann Rheum Dis 1957; 16: 494-502.

[10] Tüzün EH, Eker L, Aytar A, Daşkapan A, Bayramoğlu M. Acceptability, reliability, validity and responsiveness of the Turkish version of WOMAC osteoarthritis index. Osteoarthr Cartil 2005; 13: 28-33.

[11] Rydell NW, Balazs EA. Effect of intra-articular injection of hyaluronic acid on the clinical symptoms of osteoarthritis and on granulation tissue formation. Clin Orthop 1971; 80: 25-32.

[12] Wright KE, Maurer SG, Di Cesare PE. Viscosupplementation for osteoarthritis. Am J Orthop 2000; 29: 80-9.

[13] Wang CT, Lin J, Chang CJ, Lin YT, Hou SM. Therapeutic effects of hyaluronic acid on osteoarthritis of the knee. A meta-analysis of randomized controlled trials. J Bone Joint Surg Am 2004; 86-A(3): 538-45.

[14] Bellamy N, Campbell J, Robinson V, Gee T, Bourne R, Wells G. Viscosupplementation for the treatment of osteoarthritis of the knee. Cochrane Database Syst Rev 2006; (2): CD005321.

[15] Wobig M, Dickhut A, Maier R, Vetter G. Viscosupplementation with hylan G-F 20: a 26 week controlled trial of efficacy and safety in the osteoarthritic knee. Clin Ther 1998; 20(3): 410-23. 
[16] Dıraçoğlu D, Alptekin K, Teksöz B, Yağcı İ, Özçakar L, Aksoy C. Knee $v s$ hip single-joint intra-articular hyaluronic acid injection in patients with both hip and knee osteoarthritis: a pilot study. Clin Rheumatol 2009; 28: 1021-4.

[17] Aggarwal A, Sempowski IP. Hyaluronic acid injections for knee osteoarthritis. Systematic review of the literature. Can Fam Physician 2004; 50: 249-56.

[18] Toh EM, Prasad PS, Teanby D. Correlating the efficacy of knee viscosupplementation with osteoarthritic changes on roentgenological examination. Knee 2002; 9(4): 321-30.

[19] Lohmander LS, Dalen N, Englund G, et al. Intra-articular hyaluronan injections in the treatment of osteoarthritis of the knee: a randomised, double blind, placebo controlled multicentre trial. Hyaluronan Multicentre Trial Group. Ann Rheum Dis 1996; 55(7): 424-31.

[20] Kemper F, Gebhardt U, Meng T, Murray C. Tolerability and shortterm effectiveness of hylan G-F 20 in 4253 patients with osteoarthritis of the knee in clinical practice. Curr Med Res Opin 2005; 21(8): 1261-9.

[21] Arrich J, Piribauer F, Mad P, Schmid D, Klaushofer K, Müllner M. Intra-articular hyaluronic acid for the treatment of osteoarthritis of the knee: systematic review and meta-analysis. CMAJ 2005; 172: 1039-43.

[22] Bragantini A, Molinaroli F. A pilot clinical evaluation of the treatment of hip osteoarthritis with hyaluronic acid. Curr Ther Res 1994; 55: 319-30.

[23] Migliore A, Tormenta S, Massafra U, et al. Intra-articular administration of hylan G-F 20 in patients with symptomatic hip osteoarthritis: tolerability and effectiveness in a large cohort study in clinical practice. Curr Med Res Opin 2008; 24: 1309-16.

[24] Conrozier T, Bertin P, Bailleul F, et al. Clinical response to intraarticular injections of hylan G-F 20 in symptomatic hip osteoarthritis: the OMERACT-OARSI criteria applied to the results of a pilot study. Joint Bone Spine 2006; 73: 705-9.

(C) Uçar et al.; Licensee Bentham Open.

This is an open access article licensed under the terms of the Creative Commons Attribution Non-Commercial License (http://creativecommons.org/licenses/by-nc/ $3.0 /$ ) which permits unrestricted, non-commercial use, distribution and reproduction in any medium, provided the work is properly cited 